\title{
NON-CHLORINATED MATERIALS BASED ON ACRYLONITRILE BUTADIENE RUBBER MODIFIED WITH THERMOPLASTIC ELASTOMERS
}

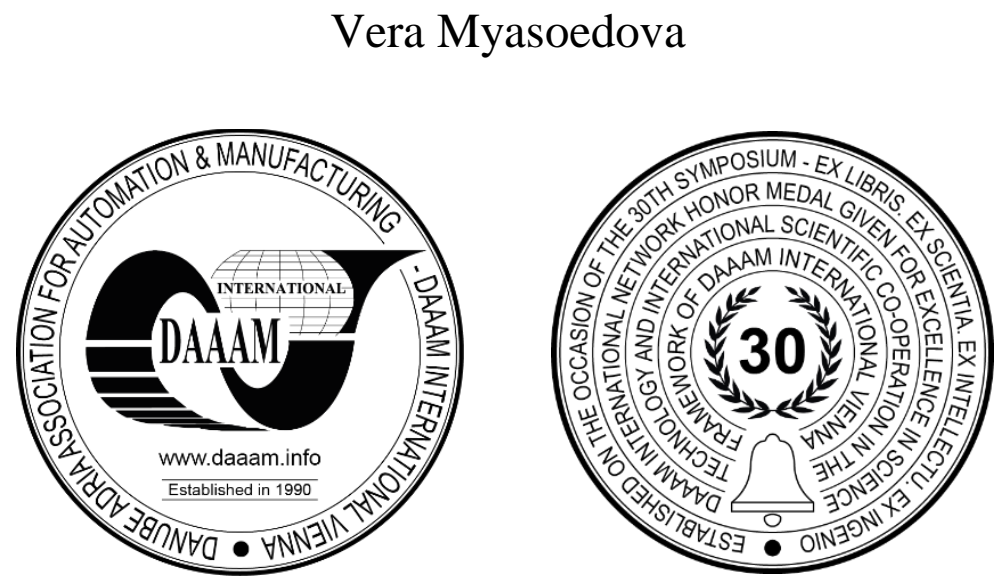

This Publication has to be referred as: Myasoedova, V[era] (2020). Non-Chlorinated Materials Based on Acrylonitrile Butadiene Rubber Modified with Thermoplastic Elastomers, Proceedings of the 31st DAAAM International Symposium, pp.0290-0298, B. Katalinic (Ed.), Published by DAAAM International, ISBN 978-3-902734-29-7, ISSN 1726-9679, Vienna, Austria

DOI: $10.2507 / 31$ st.daaam.proceedings.040

\begin{abstract}
The paper features the results of study of physical and chemical properties of composites based on blends of butadieneacrylonitrile rubber (BNR) and thermoplastic elastomer aiming at development of novel class non-clorinated marerials. Study of physical and chemical properties of blends of rubber with other synthetic polymers, for example, elastomeric materials, is of particular interest in scientific and applied sphere. Main goal based on modification of rubber by thermoplastic elastomers for substitution of polyvinil chloride component in polymer compositions and materials. They are new recipes of composites make it possible to improve the processing technology of materials and goods because are suitable for extrusion, pressing and injection molding for manufacture of quality sealing gaskets, sheets, cables, hoses, automotive components, coatings and glue compositions. The data of a complex physical and chemical study of NBR based materials with thermoelastoplast and their mixtures shows that these components are well compatible in the studied range of concentrations, whereby the produced materials, in contrast to compositions on the basis of rubber and polyvinyl chloride mixtures. Propposed novel materials are alternative to polyvinil cloride containing compositions bcause we show increased heat resistance and release no chlorinated toxic substances at use of the correspondent products and nonchlorinated polymer materials which is seen as a positive factor leading to the decrease of environmental footprint.
\end{abstract}

Keywords: Non-clorinated materials 1; rubber 2; thermoplastic elastomer 3; polyvinyl chloride 4.

\section{Introduction}

Study of physico-chemical properties of the new composites on the basis of modification of butadiene-acrylonitrile rubber acrylonitrile rubbers, containing 28 and $40 \%$ mass. acrylic acid nitrile links (produced by SIBUR AG, Russia) and thermoplastic elastomer (styrene-ethylene-butylene-styrene copolymers grade Masflex60112BLK9010U (manufactured recently as new grade by AG Rusplast company, Russia) - proposed by us - is significant in terms of scientific and applied research. The present paper is aimed the development of investigations previous published works [1], [2] on the study of influence of the nature of synthetic and natural polymers [3], [4], [5], [6] and contents of their blends on physico-chemical properties of composites on the basis of mixtures containing BNKS-40AMN rubber and styrene-ethylene-butylenestyrene copolymer (SEBS) Masflex 60112BLK9010U, and comparison of physico-chemical properties of butadiene- 
acrylonitrile rubber (BNR) and polyvinyl chloride (PVC) mixtures for further replacement of PVC by Masflex 60112BLK9010U as SEBS copolymer. This direction of researches is in correlation of industrial attempts for approach rubberize constructions filled with PVC [12].

The obtained experimental data shows that there is a possibility to add new data on physical chemistry of composites and create scientific grounds for establishment of a comprehensive approach to management of physico-mechanical features and other performance parameters of products that are manufactured on thermoplastic composite elastomers and rubber as mentioned also by [10], [11], [12], [19], [21], [22] as the effect of butadiene-acrylonitrile rubber on mechanical, thermal properties of recycling blends.

\section{Materials and Methods}

The study is conducted with use of the locally manufactured materials: BNR grade BNKS-40AMN, SEBS grade Masflex 60112BLK9010U (see Fig.1) and materials on the basis of their mixtures. Pre-preparation of mixtures of BNR grade BNKS-40AMN with addition of Masflex 60112BLK9010U with different contents of thermoplastic elastomers is performed by means of rolling and thermopressing.

Comprehensive physico-chemical examination involving Fourier-transform infrared spectroscopy, thermogravimetric analysis (TGA), differential scanning calorimetry (DSC) and thermomechanical analysis is conducted to assess the influence of addition of SEBS to the rubber and describe the specific properties of mixtures and composites made of the mixtures of these polymers.

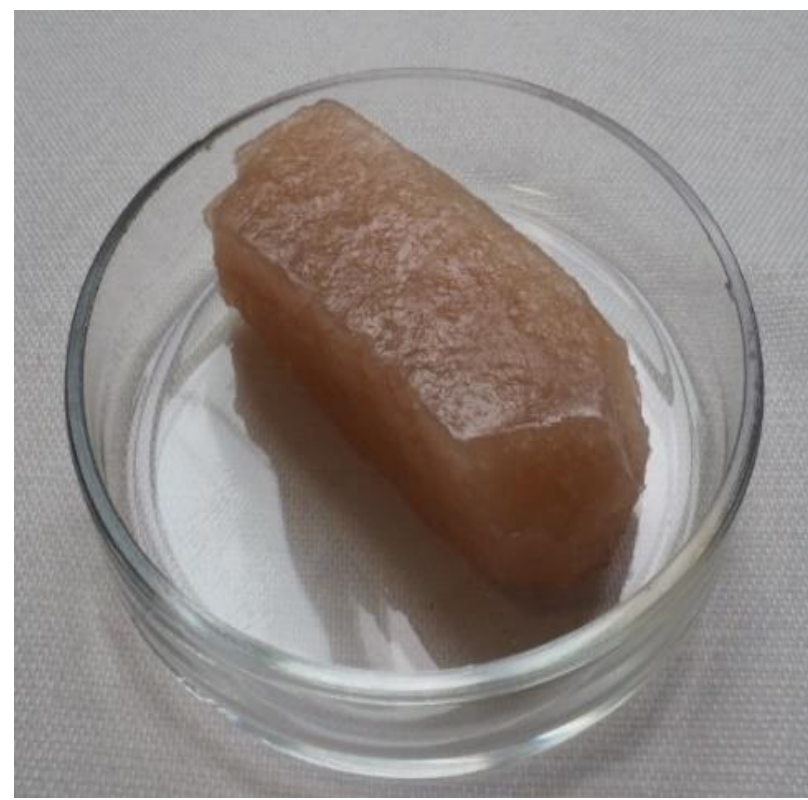

(a)

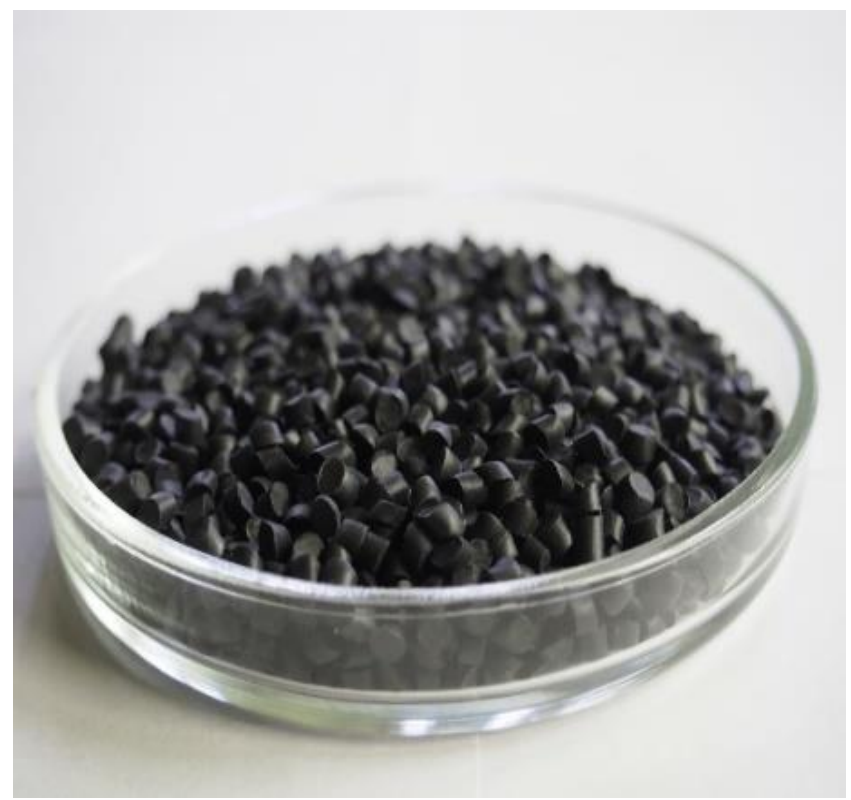

(b)

Fig. 1. Sample rubber grade BNKS-40AMN (a); sample SEBS grade Masflex (b).

\section{Results}

The paper features Fourier-transform infrared specters (FT IR specters), TGA, DSC, thermomechanical analysis curves of examined samples of SEBS grade Masflex60112BLK9010U, BNR grade BNKS-40AMN as well as mixtures of BNKS-40AMN with addition of 5\%,10\%, 15\% and 20\% mass. SEBS grade Masflex 60112BLK9010U.

\subsection{FT IR spectroscopy of the source components}

Judging by the Fourier-transform infrared specters of BNKS-40AMN (see Fig.2) we can see that there is a characteristic feature for BNKS-40AMN and for the specters of BNKS-40AMN (studied earlier by [1], [13]) - namely valence banding $-\mathrm{C} \equiv \mathrm{N}$ at $2237 \mathrm{~cm}-1$ and fluctuation of bound nitrogen at $2183 \mathrm{~cm}-1$. This peak at $2237 \mathrm{~cm}-1$ is present in rubber even at its low contents in the mixture (up to $2 \%$ mass.). Mass extinction coefficient for certain peaks of Fouriertransform IR specter, for example, of the band that relates to valence oscillations of atomic bonding between carbon and nitrogen correlates with the content of acrylonitrile in the rubber. As it is well depicted on the Fig. 3, the data obtained from Fourier-transform infrared spectroscopy of the studied SEBS are well aligned with the data from literature [16], namely for the SEBS Kraton G1650 samples (see Fig. 4). 


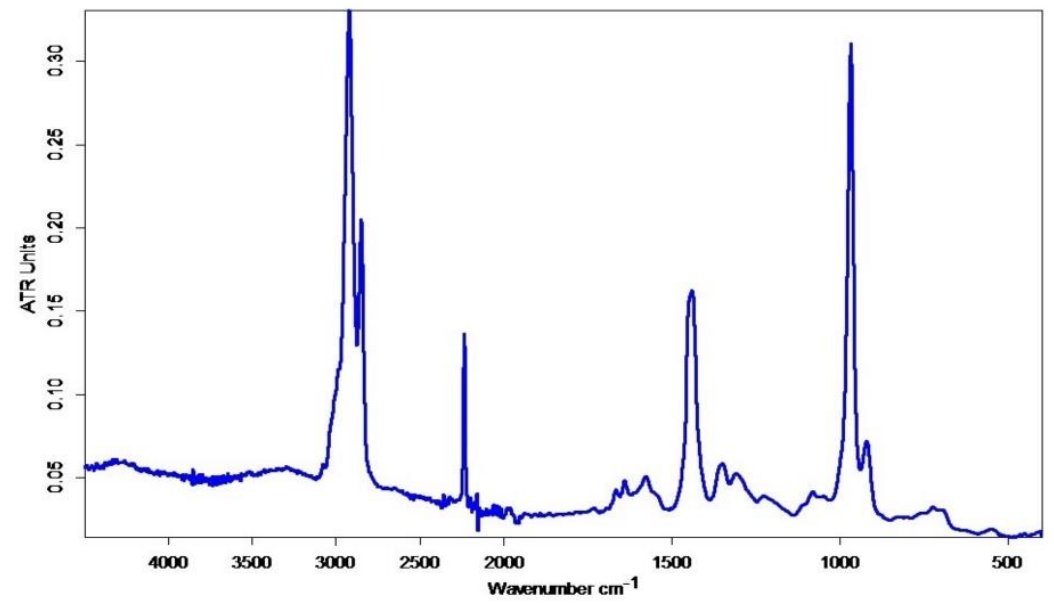

Fig. 2. Fourier-transform infrared specter of BNKS-40AMN sample.

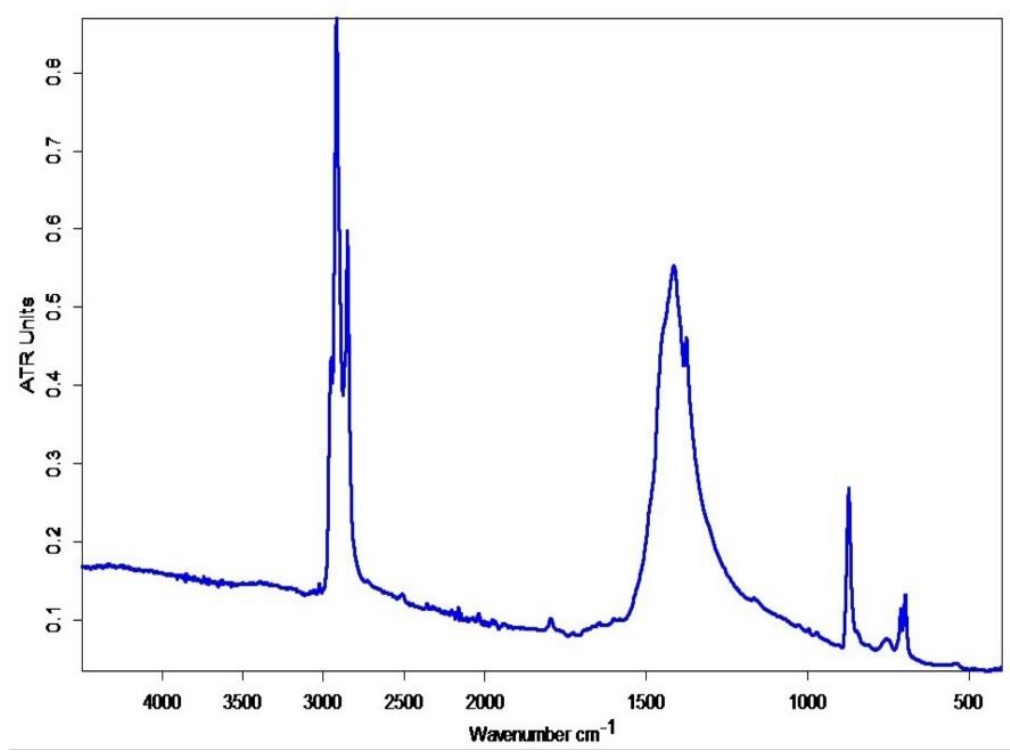

Fig. 3. Fourier-transform infrared specter of SEBS sample grade Masflex.

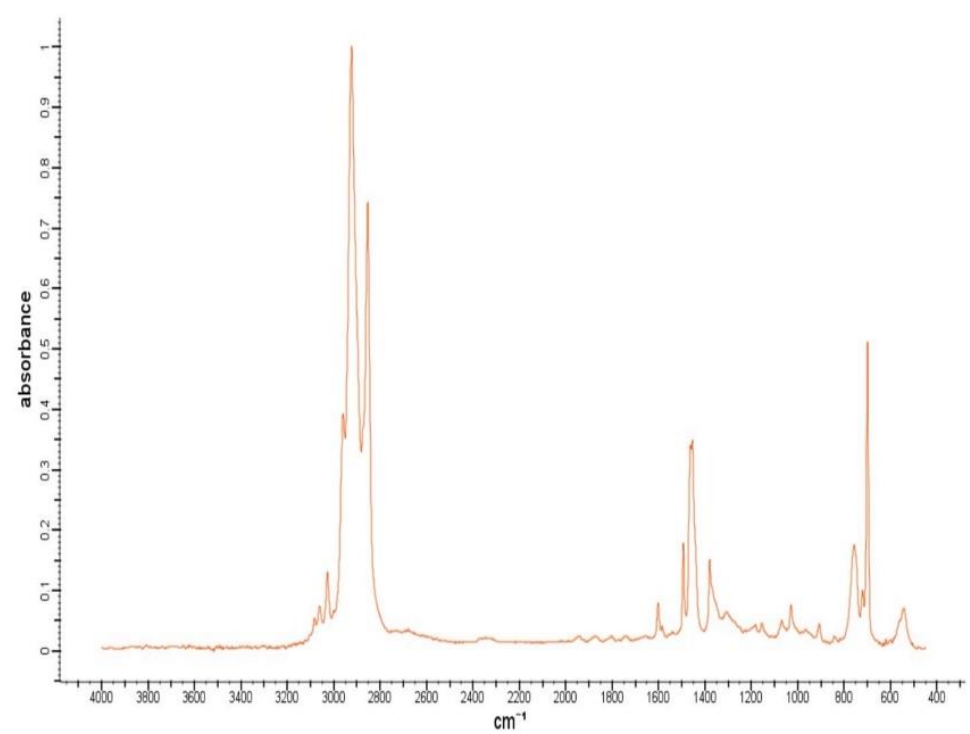

Fig. 4. Fourier-transform infrared spectroscopy of SEBS grade Kraton G1650 [16]. 


\subsection{Thermogravimetric analysis and differential scanning calorimetry of initial components}

The studied components were subject to the thermogravimetric analysis and investigations by differential scanning calorimetry method. BNKS-40AMN (see Fig. 5) shows characteristic heat resistance; mass extinction starts at heating over $400^{\circ} \mathrm{C}$. The rubber studied by us is not inferior in characteristics to foreign analogues [7].

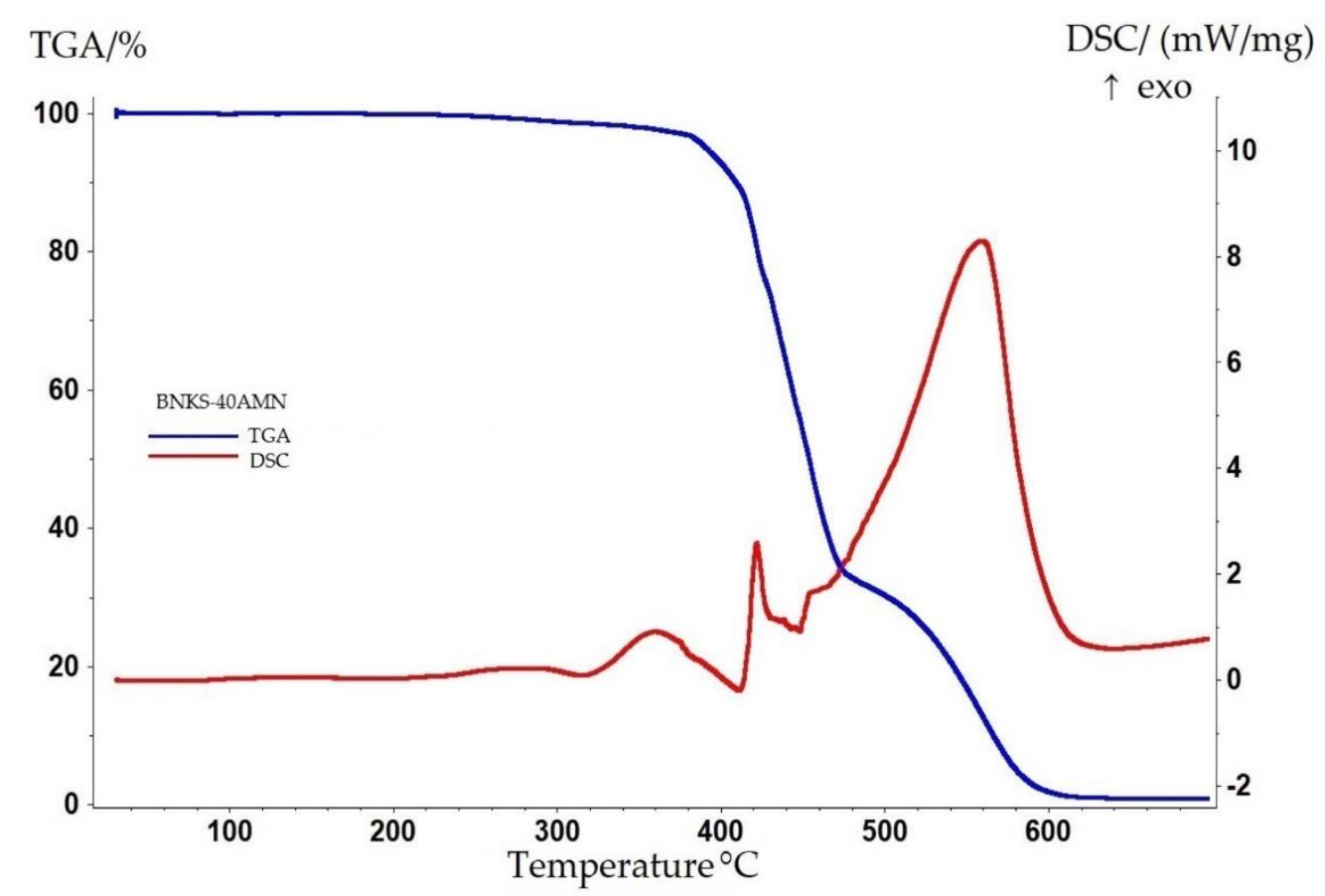

Fig. 5. Curves of thermogravimetric analysis and differential scanning calorimetry for BNKS-40AMN.

Range of mass extinction start temperatures for SEBS Masflex 60112BLK9010U (Fig. 6) is within 210-230 ${ }^{\circ}$.

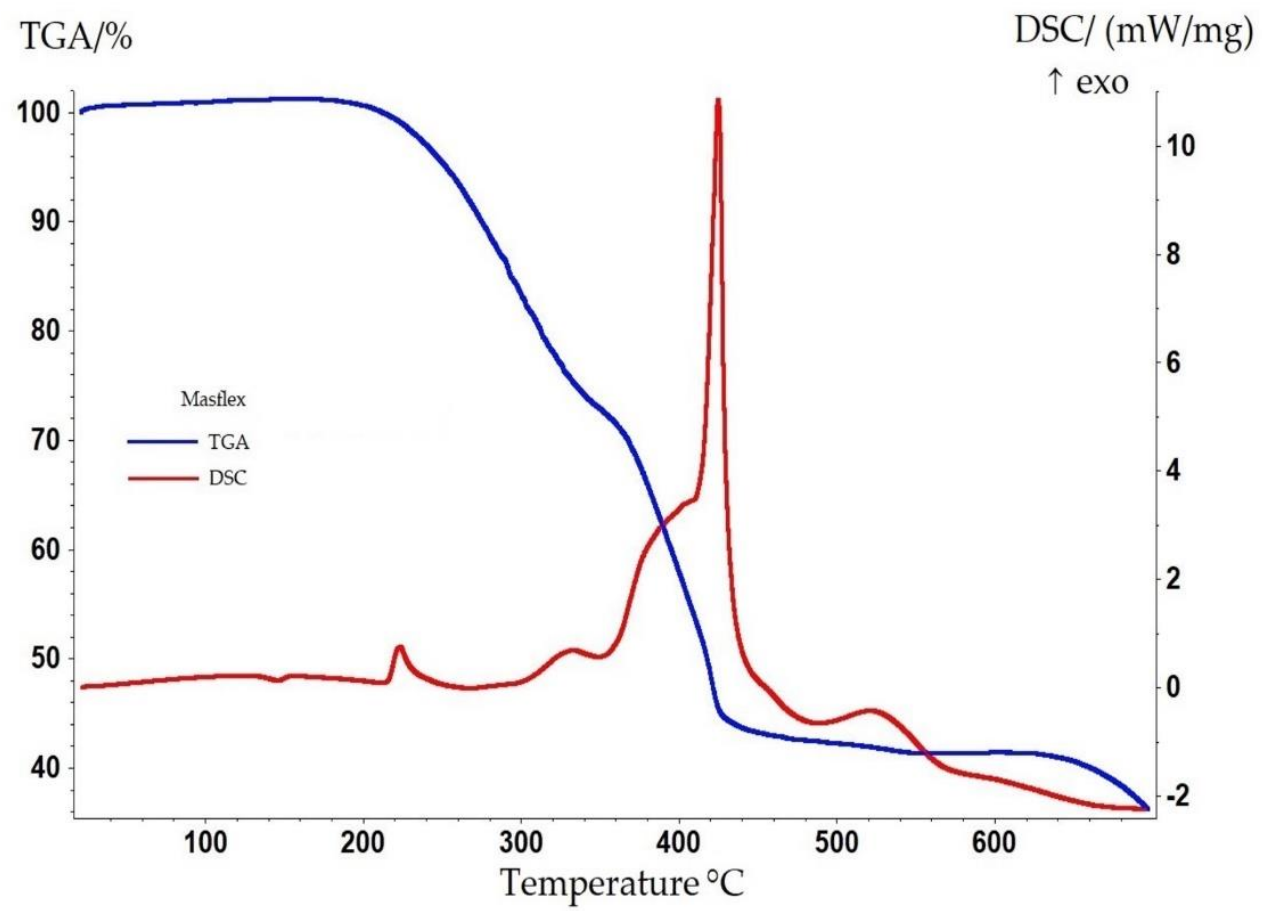

Fig. 6. Experimental curves of thermogravimetric analysis and differential scanning calorimetry for SEBS grade Masflex. 


\subsection{Thermo-mechanical analysis of the thermoplastic elastomer component (SEBS)}

SEBS, grade Masflex has the highest strength, as it is seen in our experimental data - thermo-mechanical analysis curve (see Fig. 7), and it also has the most stable structure compared to other thermoplastic elastomers (for example, in comparison to styrol-butadien-styrol copolymer, grade SBS 30-01 (manufactured by SIBUR Company), which increases and provides for the resistance against high temperatures, ozone, UV-radiation and exposure to aggressive environments.

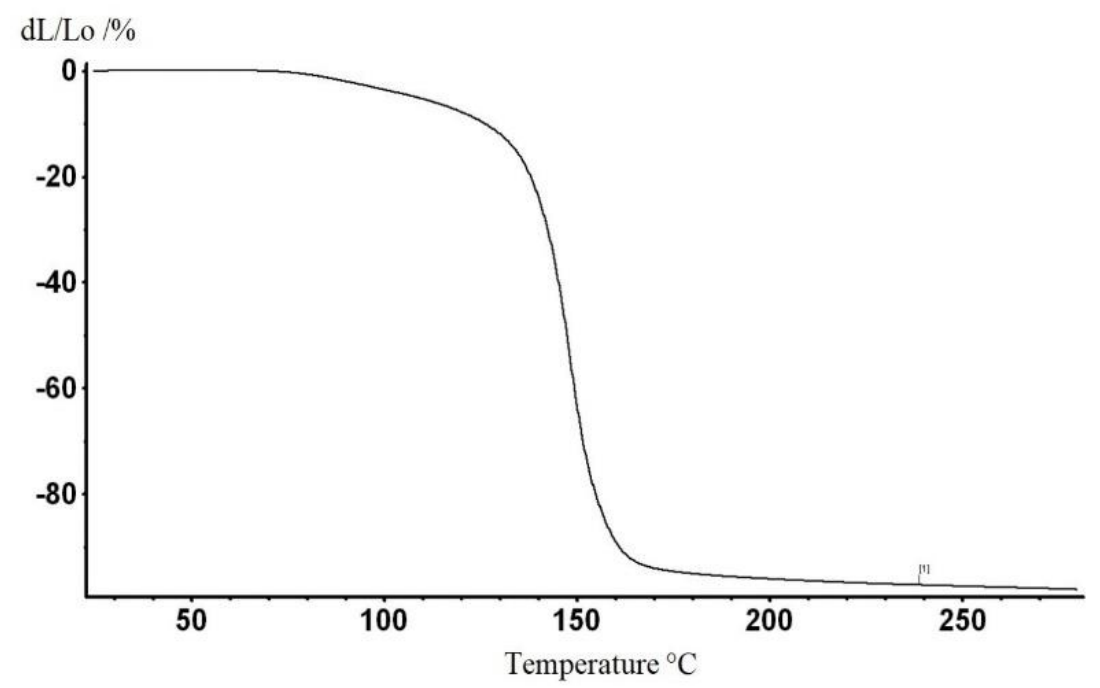

Fig. 7. Curve of thermomechanical analysis of SEBS grade Masflex.

\subsection{Fourier-transform spectroscopy of mixtures of components BNKS-40AMN and SEBS.}

Fourier Infrared specters of mixtures of components of BNKS-40AMN containing 5\%, 10\%, 15\% and 20\% SEBS Masflex 60112BLK9010U, as represented on the Fig. 8, show that the band 2236-2237 $\mathrm{cm}^{-1}$ of valent oscillation of triplecoupled atoms $-\mathrm{C} \equiv \mathrm{N}$ doesn't change its position, but its intensity decreases along the increase of SEBS content in the mixture with rubber.

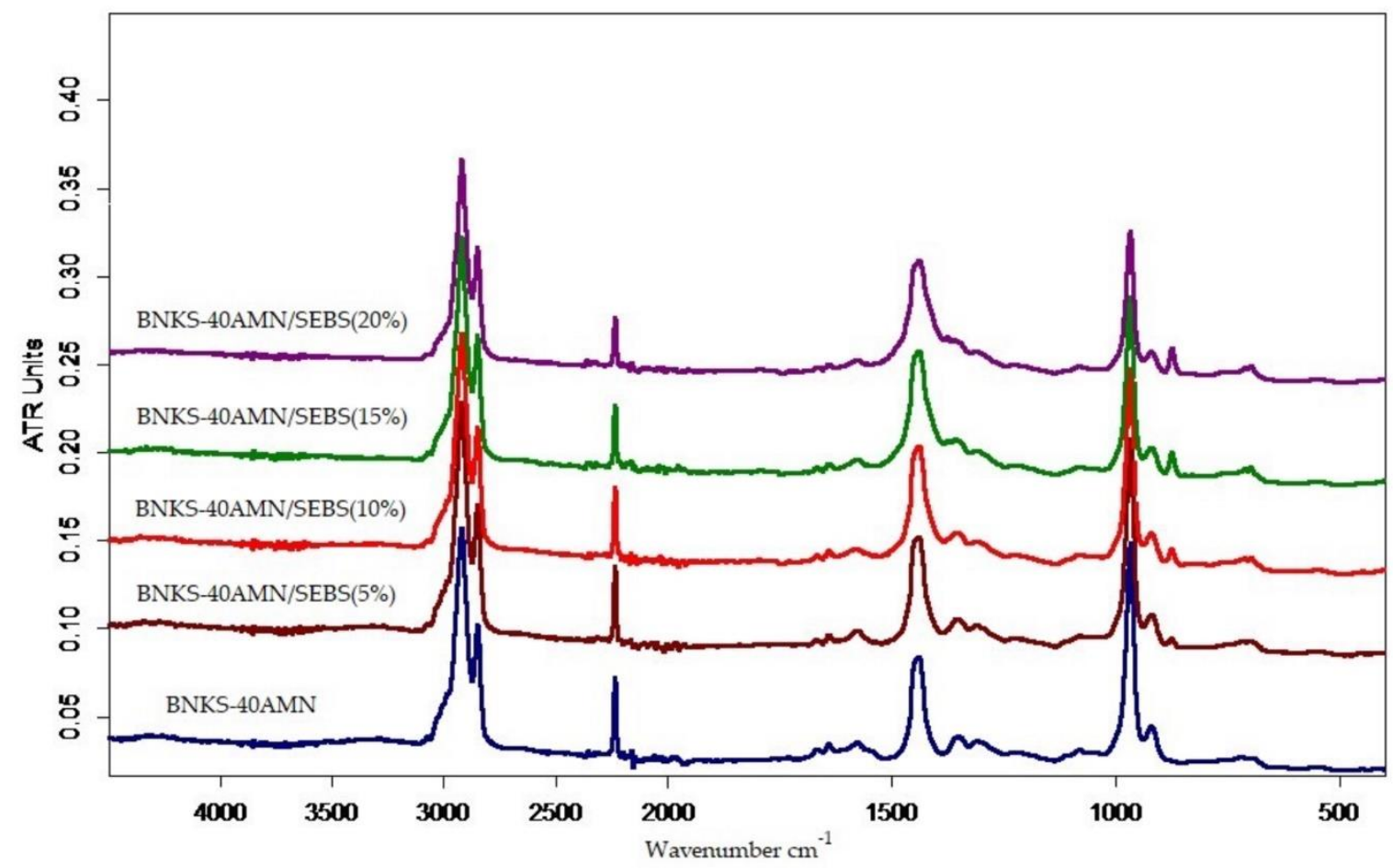

Fig. 8. Fourier-transform infrared specters of mixtures of components of BNKS-40AMN containing 5\%, 10\%, $15 \%$ and $20 \%$ SEBS grade Masflex. 
The intensity of deformation oscillations band of $\mathrm{C}-\mathrm{H}$ connections (1-4 cis-isomers) at $1310,1350,1420 \mathrm{~cm}^{-1}[18]$ changes insignificantly towards the smaller wave numbers, and deformation oscillation bands $\mathrm{C}-\mathrm{H}$ and $=\mathrm{CH} 2$ at 910 $\mathrm{cm}^{-1}$ - decline insignificantly at $20 \%$ content of SEBS in the mixtures. Fourier Infrared specters of the compositions on the basis of mixtures of rubber and SEBS of different content are additive, i.e. they represent a simple superposition of specters of individual components in which the spectral input of each component is proportional to its relative content in the mixture. Absence of distinct new characteristic bands in specters of mixtures indicates that there is no formation of a chemical compounding between the components (i.e. there are no manifestations of breaking up old and forming new covalent bonds).

Small shifts in positions of peaks of extinction bands of the components of mixture, in case of change of the content of mixtures, suggest that the interaction between the components of mixture (rubber and SEBS ) comes down to the changes of physical structure and correlation between the amorphous-crystalline domains than to intermolecular interactions. Still this assumption requires a more thorough examination due to the fact that the structure of rubber is able to transform during heat treatment, presumably, because of the participation of the residual non-saturation in cross-linking reactions. Apparently, chemical interaction between these components of rubber and SEBS grade Masflex 60112BLK9010U is absent, but there is a change of structure on the physical level. And further will be demonstrated DSC curves confirmed this facts.

\subsection{Thermogravimetric analysis and differential scanning calorimetry of mixtures of components of BNKS-4OAMN and} SEBS.

The figures below (see Fig. 9 and Fig. 10) demonstrate experimental results of thermogravimetric analysis and differential scanning calorimetry curves of mixtures of components of BNR grade BNKS-40AMN containing 5\% mass., $10 \%$ mass., $15 \%$ mass. and 20\% mass. SEBS grade Masflex 60112BLK9010U. Thermogravimetric analysis curves show that introduction of Masflex additives into rubber within the studied range of mixtures' contents (up to 20\% mass.) leads to a significant increase in heat resistance of samples: the beginning of mass extinction is related to the range of temperatures close to $400^{\circ} \mathrm{C}$.

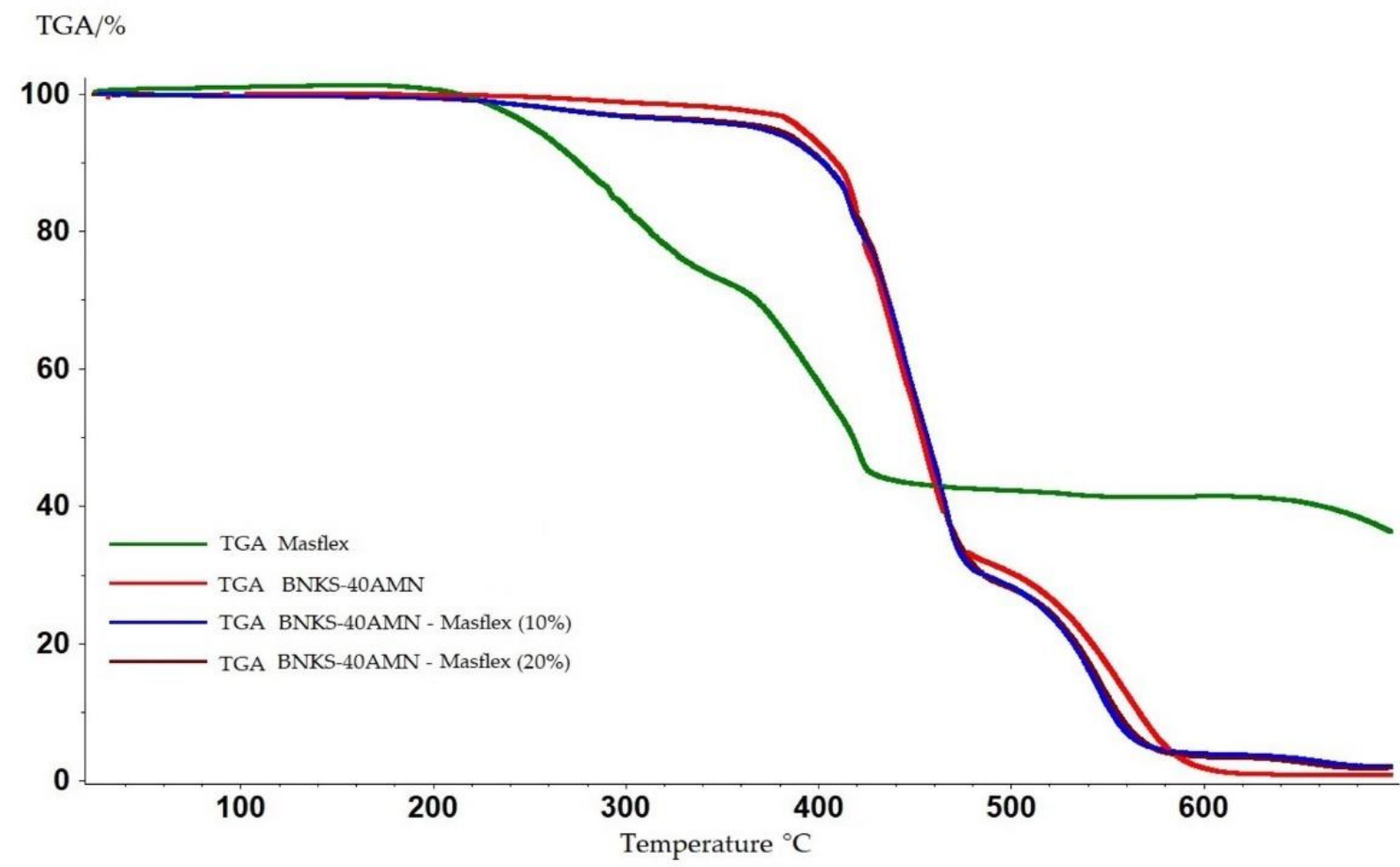

Fig. 9. Thermogravimetric analysis curves of SEBS grade Masflex component (green), BNKS-40AMN component (red) and their mixtures containing 10\% mass. and 20\% mass. of SEBS Masflex (blue and brown correspondently)

Addition of SEBS grade Masflex 60112BLK9010U into rubber doesn't practically decrease heat resistance of mixtures of BNR grade BNKS-40AMN with SEBS Masflex 60112BLK9010U additives. In the results obtained by us [16], it was found that the rubber containing butadiene-nitrile rubber grade BNKS-40 AMN is characterized by increased heat resistance. An increase in the rubber content leads to an increase in heat resistance. Increased strength and relative elongation at break is registered in mixture-type thermoplastic elastomers such as SEBS grade Masflex 60112BLK9010U (Fig.7). 


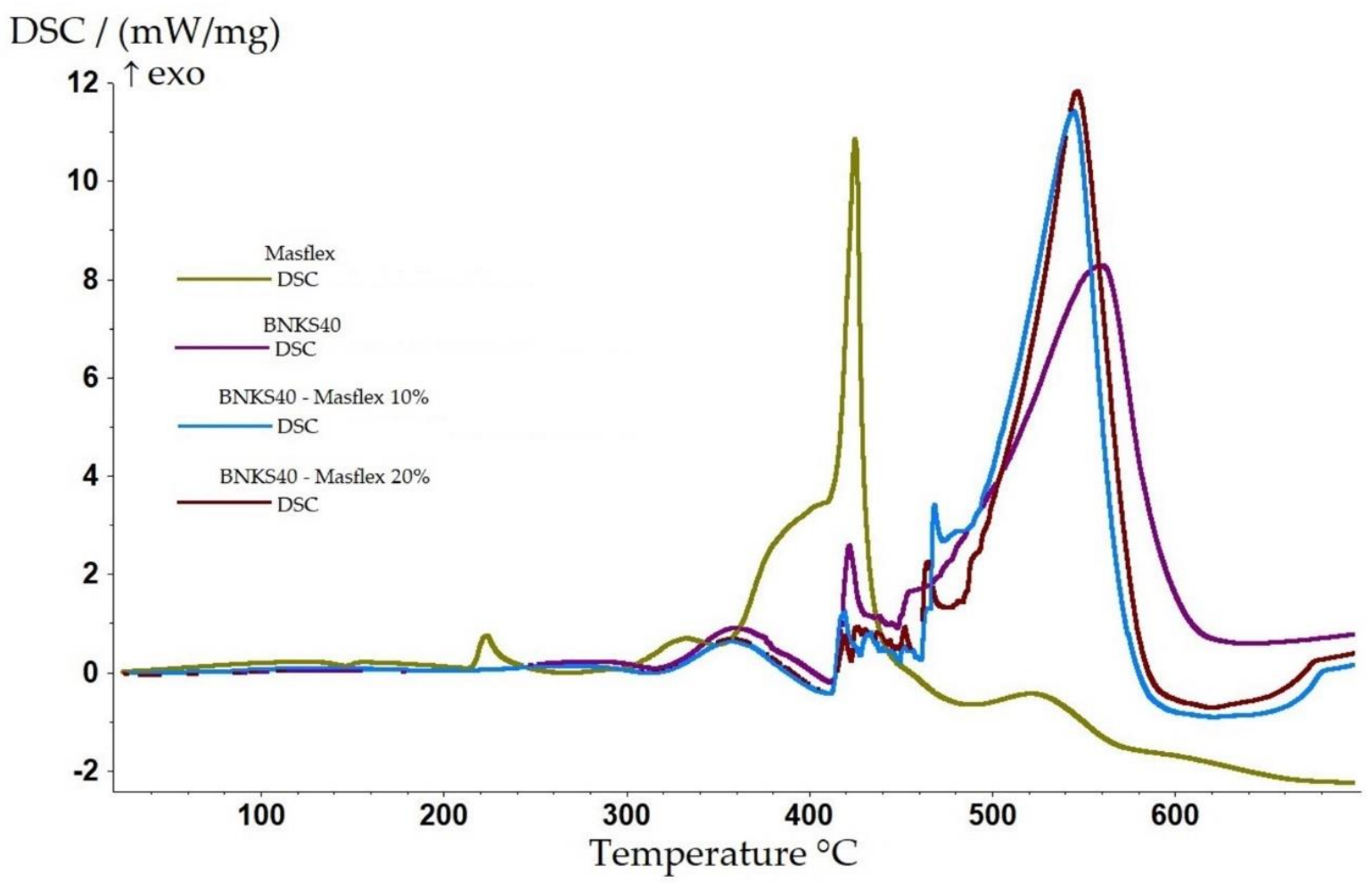

Fig.10. Curves of differential scanning calorimetry of components of rubber grade BNKS-40AMN (violet), SEBS grade Masflex (green) and mixtures containing 10\% (light-blue) and 20\% (red) SEBS Masflex.

3.6 Comparison of physico-chemical properties of mixtures of NBR grade BNKS-40AMN and SEBS grade Masflex with properties of mixtures of butadiene-nitrile rubber(NBR) and $P V C$

The mixtures of butadiene-nitrile rubber (NBR) with PVC are broadly used in such products as hoses and sealants. The comparative study of the systems on the basis of the data of thermogravimetric analysis shows that the mass extinction of the mixture of BNK with PVC takes place in two stages. The first stage of mass extinction takes place at the temperature of $250^{\circ} \mathrm{C}$ and constitutes $17 \%$ mass. of the analyzed sample. Second stage of mass extinction takes place at the temperature of $430^{\circ} \mathrm{C}$ and constitutes about $55 \%$ mass.[7]. Besides, emission of undesirable chlorinated volatile products as a result of thermal decompression of mixtures of rubber with PVC was appeared.

We compared the experimentally obtained curves of thermogravimetric analysis of mass extinction of BNKS40AMN, SEBS grade Masflex and mixtures of rubber grade BNKS-40AMN and SEBS grade Masflex with the data taken from literature on thermal decomposition of the same grade of rubber and PVC mixtures [7], [9]. The obtained results of structural properties by FT Infrared spectroscopy of BNR and thermoelastoplast of styrene type are in good correlation with previous published results [19]. TGA/DSC investigation for component NBR correlated with published in [2] and [7]. Investigations of properties of blends of NBR and styrene copolymer - it is a new results confirming by compared other studies of components properties published recently [16].

\section{Discussion}

Fourie-transform IR specters of mixtures of BNR grade BNKS-40AMN and SEBS grade Masflex 60112BLK9010U in broad range of compositions indicate the absence of chemical modification. In other cases described in [16],[21] the surface modification of the same styrene nature elastomer via UV-induced graft polymerization under chemical agent influence. The same facts we can predict based on the preliminary investigations of analogous systems based on blends of rubbers (BNKS-28AMN and BNKS-40AMN) with SBS grade 30-01. The obtained data opens new pathways for creation of the new two- and multi-component mixture-type compositions suitable for manufacturing of materials for manufacture of cables, sealants, binders and glues. Increase of heat resistance and thermodynamic compatibility of SEBS grade Masflex in mixtures with BNKS-40AMN is registered during the research of components and mixtures of different contents with use of thermogravimetric analysis and differential scanning calorimetry. Thermodynamic compatibility of components in the studied range of compositions is achieved due to strong elastification of NBR by copolymer of ethylene-butylene-styrene grade Masflex 60112BLK9010U. 


\section{Conclusions}

The paper features comparison of thermogravimetric parameters of thermal decomposition of the materials based on compositions, that were developed by us (with different mass contents of SEBS grade Masflex 60112BLK9010U additives) and differ from the behavior of the compositions of nitrile butadiene rubber (NBR) and PVC mixtures that were applied earlier [7],[9] whereby our compositions and materials have no $\mathrm{HCl}$ in decomposition products and no toxic substances in atmosphere. It is a well-known fact that the destruction of material takes effect during the thermal impact on the mixtures of BNR and PVC as well as due to the effect of UV radiation, leading to release of hydrogen chloride and carbon monoxide, that are harmful to human body, therefore one of the aims of the present study was the selection of an effective component that wouldn't have adverse environmental impact.

Replacement of PVC at manufacturing of polymer compositions and use of products manufactured on their basis and being subject to thermal impact and UV radiation opens up the possibility of decrease of adverse environmental effects, which provides for environmental safety, for example, in the processes of use of cables in conditions that provoke the decomposition of composites and release of toxic substances in the face of ignitions and wildland fires. Good thermodynamic compatibility of components (NBR and SEBS grade Masflex ) of polymer blends in investigated area of concentrations is achieved due to strong elastification of rubber by copolymer of ethylene-butylene-styrene as following from complex physical and chemical investigations

Blends of NBR and SEBS grade Masflex have a lot of advantages versus blends of rubber with PVC and recommend to industrial approach. Polymer blends based on BNR and thermoelastoplasts - the best alternative to blends with PVC. The development of presented experimental work will focus on the new kinds of styrene copolymer and innovations for development of the new materials manufacture for market filled-in by organic and non-organic nanoparticles and dyes. In multicomponent blends thermoelastoplast will play role of compatibilizer and will serve against expholiation of nanoparticle.

\section{Acknowledgments}

The work is conducted in frames of the Public Task 45.11 with the support of the Program 35 of the Presidium of the Russian Academy of Sciences "Scientific Basis for Creation of the New Functional Materials", Public Task "Development of Methods for Creation of Nanostructured Polymeric, Biopolymeric and Composite Materials and their Target Modification with a Wide Range of Practical Applications, No. AAAA-A17-117040610309-0, No. 0082-20140009"

Grateful for experimental support by PhD Serik Akhmetov, senjor researcher of Semenov FRC ChPh RAS Andrey Grachev, engineer-researcher Alexey Tronkin

\section{References}

[1] Leber, M[arian], Selinek, A[leksandra](2019. The Influence of the Supplier on the Successful New Product Development, Proceedings of the 30th DAAAM International Symposium, pp/0038-0045, B/Katalinic (ed/) Published by DAAAM International, ISBN 978-3-902734-22-8, ISSN 1726-9679, Vienna, Austria, DOI: 10.2507/30th DAAAM.proceedings.005

[2] Myasoedova, V[era], Taran, I.A. (2019), The Influence of the Composition of Ethyl Cellulose - Rubber Blends on Formation of Thermoplastic Composites. Polymer Science, Series D, Volume 12, N1, pp 2-8.

[3] Baranova, N.V.; Pashina, L.A.; Kostochko A.V. (2012), The relationship of the chemical structure of the surface of butadiene-nitrile rubbers with the surface energy and acid-base characteristics. Bulletin of Kazan technological university, Volume 15, No. 15, pp. 172-176.

[4] Zhong, R.; Zang, Z., Zhao, H. et al. (2018), Improving-Oxidative stability of nitrile rubber composites by functional graphene oxides. Materials., pp. 921-936.

[5] Khare, R.A. (2011), Melt-mixed polypropylene/acrylonitrile-butadiene-styrene blends with multiwall carbon nanotubes: Effect of compatibilizer and modifier on morphology and electrical conductivity. J. of Applied Pol.Sci. Volume 120, No. 5, pp. 2663-2677.

[6] Lusova L R., Myasoedova, V.V.; Kotova S.V. (2009), Patent RU No 2577851. Byull.Izobret., No13.

[7] Pappa, A.; Mikedi, K., Agapiou, A.; Karma, S.; Pallis, G.C.; Statheropoulos, M.; Burke. M. (2011), TG-MS analysis of nitrile butadiene rubber blends (NBR/PVC). Journal of Analytical and Applied Pyrolysis, Vol. 92, No.1, pp. 106110.

[8] Danwanichakul, P.; Pohom, W.; Yingsampancharoen, J. L. (2019), Quebrachitol from acidic serum obtained after rubber coagulation of skim natural rubber latex. Industrial Crops and Products, N137, pp157-161.

[9] Dao, F.K.; Gaidadin, A.N.; Gorkovenko, D.A., Navrotsky, V.A. (2019), Modification of Natural Rubber with Poly (diallyldimethylammonium chloride) and Polyvinyl Chloride. Russian Journal of Applied Chemistry, Volume 92, N6, pp 759-766. 
[10] Garhwal, A.; Maiti, S.N. (2016), Influence of styrene-ethylene-butylene-styrene (SEBS) copolymer on the shortterm static mechanical and fracture performance of polycarbonate (PC)/SEBS blends. Polymer Bulletin, Volume 73, N6, pp 1719-1740.

[11] Ouarhim, W.; Essabir, H.; Bensalah, M.O.; Rodrigue, D.; Bouhfid, R.; \& Qaiss, A. el kacem. (2019), A Comparison between Sabra and Alfa Fibers in Rubber Biocomposites. Journal of Bionic Engineering. Volume 16, N4, pp 754767.

[12] Jan, F.; Nasser, A.; Fahadullah, M.; Akbar H. (2019), Conventional and Rubberize Concrete Cylinders Filled with PVC Tube. International Journal of Engineering Works, Volume 6, N5, pp 172-175.

[13] Suresh, S. S.; Mohanty, S.; \& Nayak, S.K. (2019), Effect of Nitrile Rubber on Mechanical, Thermal, Rheological and Flammability Properties of Recycled Blend. Process Safety and Environmental Protection. Elsevier, Volume 123, pp 370-378.

[14] Samir, M.; MorsiHeba M, MohamedSalwa A., El-Sabbagh A. (2019), Polyesteramidesulfone as novel reinforcement and antioxidant nanofiller for NBR blended with reclaimed natural rubber. Materials Chemistry and Physics, Volume 224, pp 206-216.

[15] Song X., Li X, Yan H. (2019), Preparation and microwave absorption properties of MWCNTs/Fe3O4/NBR composites, Volume 100.

[16] Serik N.Akhmetov, Vera V.Myasoedova, Andrey V.Granchev (2020), Non-Clorinated Polymer Composition Based On Acrylonitrile Butadiene Rubber And Styrene Copolymer. Chemical Safety Sciences, 4(1), pp.151-159

[17] Sandalov, S.I.; Feofanova, O.N.; Reznikov, M.S.; Ashmarin, N.F.; Gnezdilov, D.O.; Koltsov N.I. (2014), Development of thermally aggressive rubber based on nitrile butadiene rubbers. Bulletin of Kazan technological University, Volume 17, No. 3, pp 108-110.

[18] Kuptsov, A.Kh.; Zhizhin G.N.; (2013), Fourier-CR and Fourier-IR spectra of polymers. Technosphere: Moscow, Russia, p. 696.

[19] https://spectrabase.com/spectrum/4ydezmY7VEU?a=SPECTRUM_4ydezmYVEU(acceces 26.02.2020)

[20] Taib, M. N. A. M., Yehye, W. A., \& Julkapli, N. M. (2019), Influence of Crosslinking Density on Antioxidant Nanocellulose in Bio-degradation and Mechanical Properties of Nitrile Rubber Composites. Fibers and Polymers, Volume 20, N1, pp 165-176.

[21] Luan, S.; Zhao, J.; Yang, H.; Shi, H.; Jin, J.; Li, X.; Liu, J.; Wang, J.; Yin, J.; Stagnaro, P. (2012), Surface modification of poly(styrene-b-(ethylene-co-butylene)-b-styrene) elastomer via UV-induced graft polymerization of N-vinyl pyrrolidone. Colloids and surfaces. B, Biointerfaces, Volume 93, pp127-34.

[22] Myasoedova,V.V(2012), Environmentally friendly fuel briquettes and pellets based on renewable lignocellulosic raw material and recycling thereof. Polymer Science, Series D, Glues and sealing materials, Vol. 5, No.3, pp. 213218. 